\title{
Adherence to nutritional guidelines in pregnancy: evidence from the Growing Up in New Zealand birth cohort study
}

\author{
Susan MB Morton ${ }^{1,2}$, Cameron C Grant ${ }^{1,2,3,4, *}$, Clare R Wall ${ }^{1,2,5}$, \\ Polly E Atatoan Carr ${ }^{1,2,6}$, Dinusha K Bandara ${ }^{1,2}$, Johanna M Schmidt ${ }^{1,2,7}$, \\ Vivienne lvory ${ }^{1,2,8}$, Hazel $M$ Inskip ${ }^{9}$ and Carlos $A$ Camargo $\mathrm{Jr}^{10}$
}

${ }^{1}$ Growing Up in New Zealand, School of Population Health, The University of Auckland, Private Bag 92019, Auckland, New Zealand: ${ }^{2}$ Centre for Longitudinal Research - He Ara ki Mua, The University of Auckland, Auckland, New Zealand: ${ }^{3}$ Paediatrics: Child and Youth Health, The University of Auckland, Auckland, New Zealand: ${ }^{4}$ Starship Children's Hospital, Auckland District Health Board, Auckland, New Zealand: ${ }^{5}$ Discipline of Nutrition, School of Medical Sciences, The University of Auckland, Auckland, New Zealand: ${ }^{6}$ Waikato Clinical School, The University of Auckland, Auckland, New Zealand: ${ }^{7}$ School of Social Sciences, University of Waikato, Hamilton, New Zealand: ${ }^{8}$ Department of Public Health, School of Medicine and Health Sciences, University of Otago, Wellington, New Zealand: ${ }^{9}$ MRC Lifecourse Epidemiology Unit, University of Southampton, Southampton, UK: ${ }^{10}$ Emergency Medicine, Massachusetts General Hospital, Harvard Medical School, Boston, MA, USA

Submitted 23 May 2013: Final revision received 2 January 2014: Accepted 6 March 2014: First published online 9 April 2014

\begin{abstract}
Objective: To determine adherence to nutritional guidelines by pregnant women in New Zealand and maternal characteristics associated with adherence. Design: A cohort of the pregnant women enrolled into New Zealand's new birth cohort study, Growing Up in New Zealand.

Setting: Women residing within a North Island region of New Zealand, where onethird of the national population lives.

Subjects: Pregnant women ( $n$ 5664) were interviewed during 2009-2010. An FFQ was administered during the face-to-face interview.

Results: The recommended daily number of servings of vegetables and fruit $(\geq 6)$ were met by $25 \%$ of the women; of breads and cereals ( $\geq 6)$ by $26 \%$; of milk and milk products $(\geq 3)$ by $58 \%$; and of lean meat, meat alternatives and eggs $(\geq 2)$ by $21 \%$. One in four women did not meet the recommendations for any food group. Only 3\% met all four food group recommendations. Although adherence to recommendation for the vegetables/fruit group did not vary by ethnicity $(P=0.38)$, it did vary for the breads/cereals, milk/milk products and meat/eggs groups (all $P<0 \cdot 001$ ). Adherence to recommendations for the vegetables/fruit group was higher among older women $(P=0 \cdot 001)$; for the breads/cereals group was higher for women with previous children $(P<0.001)$ and from lower-income households $(P<0 \cdot 001)$; and for the meat/eggs group was higher for women with previous children $(P=0.003)$ and from lower-income households $(P=0.004)$. Conclusions: Most pregnant women in New Zealand do not adhere to nutritional guidelines in pregnancy, with only $3 \%$ meeting the recommendations for all four food groups. Adherence varies more so with ethnicity than with other sociodemographic characteristics.
\end{abstract}

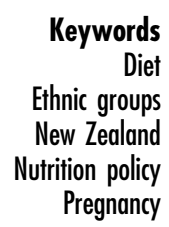

Good nutrition is necessary to maintain health during pregnancy. Nutrition during pregnancy has effects on fetal health and pregnancy duration, and longer-term effects on the offspring's health during childhood and adulthood ${ }^{(1,2)}$.

Malnutrition, both macro- and micronutrient, is prevalent in women and children globally ${ }^{(3)}$. In developing countries undernutrition of both macro- and micronutrients remains the major determinant of maternal and child health $^{(3)}$. In developed countries, such as New Zealand (NZ), maternal and child malnutrition is predominantly a combination of macronutrient overnutrition and micronutrient undernutrition ${ }^{(4)}$.

At the NZ 2008/2009 National Nutrition Survey, obesity was present in $14 \%$ of women aged $15-19$ years, $25 \%$ of those aged $20-30$ years and $28 \%$ of those aged $31-50$ years ${ }^{(5,6)}$. This represented a $30 \%$ increase in obesity prevalence among women of all ages compared with the prevalence described at the 1997 National Nutrition Survey ${ }^{(7)}$.

The available data on maternal micronutrient nutrition in NZ are also concerning. Fe deficiency prevalence among 
women aged 15 years and over increased from $3 \%$ in 1997 to $7 \%$ in $2008 / 2009^{(5)}$. Nineteen per cent of newborns in NZ have a 25 -hydroxyvitamin D concentration $<25 \mathrm{nmol} / \mathrm{l}$, a level sufficiently low to place them at risk of rickets ${ }^{(8,9)}$. As vitamin D status at birth is determined by maternal vitamin $\mathrm{D}$ status, it is likely that a similarly high proportion of pregnant women in NZ are also deficient in vitamin $\mathrm{D}^{(10)}$.

National dietary recommendations for pregnant women in NZ were published by the Ministry of Health in $2006^{(11)}$. The recommended numbers of daily servings of foods from the four main food groups (vegetables and fruit; bread and cereals; milk and milk products; lean meat, meat alternatives and eggs) were based upon nutrient requirement estimates during pregnancy for Australia and NZ (Table 1) ${ }^{(11,12)}$. The dietary guidelines suggest that people try to choose low-fat dairy options and wholegrain cereals.

There is limited information about the diets of pregnant NZ women. Studies that have been reported to date have been small and non-representative of the population's ethnic and socio-economic diversity ${ }^{(13-17)}$. Thus it is not possible to establish if the NZ recommendations regarding food group consumption for pregnant women are being met.

In the present study we sought to describe the overall dietary intake as compared with the recommended food and nutrition guidelines ${ }^{(11)}$. Our aim was to determine adherence to nutritional guidelines by pregnant women in NZ and to describe characteristics associated with adherence.

\section{Methods}

We utilised NZ's new pre-birth cohort study, Growing Up in New Zealand. This sample of pregnant women was recruited to provide information that is broadly generalisable to all current NZ births ${ }^{(18)}$. All pregnant women with an estimated delivery date between 25th April 2009 and 25th March 2010, residing within a geographical region defined by three adjacent area health board regions (Auckland, Counties - Manukau and Waikato), where approximately one-third of the country's population resides, were eligible to participate ${ }^{(18)}$. There were no other inclusion or exclusion criteria $^{(18)}$. Ethical approval was obtained from the Ministry of Health Ethics Committee. Written informed consent was obtained from all participating women.

A total of 6822 women consented and completed the antenatal interview. Enrolled women were comparable to the most recent NZ national birth statistics in relation to maternal age, ethnicity, parity and indicators of socioeconomic position ${ }^{(19)}$. The Growing Up in New Zealand cohort comprises 6846 children at birth ${ }^{(18)}$.

A face-to-face computer-assisted interview was completed with each enrolled woman. Dietary data were gathered using a semi-quantitative, forty-four-item FFQ administered during the interview. In order to minimise recall bias only women interviewed before the child's birth were included in this study of dietary patterns ( $n$ 5664).

The FFQ collected data that allowed description of the frequency of consumption of foods in the four main food groups (Table 1). Consistent with the national dietary recommendations, only one serving of juice or one serving of dried fruits could count towards the total number of servings of fruit per day ${ }^{(11)}$. The guidelines state that wholegrain cereals and low/reduced-fat milk products should be chosen. Therefore we described both the total number of daily servings of breads and cereals and also the number of daily servings of healthier breads and cereals (high-fibre white, brown bread, wholemeal and wholegrain

Table 1 New Zealand Ministry of Health recommendations for the number of servings of each of the four core food groups during pregnancy and foods that were included in the description of food group consumption ${ }^{(11)}$

\begin{tabular}{|c|c|c|c|}
\hline Food group & Foods in group & $\begin{array}{l}\text { Recommended number of } \\
\text { servings }\end{array}$ & $\begin{array}{l}\text { Specific foods included in or excluded from } \\
\text { analysis of adherence to food group serving } \\
\text { recommendations }\end{array}$ \\
\hline \multirow[t]{2}{*}{$\begin{array}{l}\text { Vegetables and } \\
\text { fruits }\end{array}$} & $\begin{array}{l}\text { Vegetables and fruits } \\
\text { (includes fresh, frozen, } \\
\text { canned and dried) }\end{array}$ & $\begin{array}{l}\text { At least } 6 \text { servings/d (at least } \\
4 \text { servings of vegetables and } \\
2 \text { servings of fruit) }\end{array}$ & $\begin{array}{l}\text { Hot chips, French fries, wedges or kumara chips } \\
\text { not included }\end{array}$ \\
\hline & & $\begin{array}{l}\text { Only } 1 \text { serving of juice or } 1 \text { serving } \\
\text { of dried fruit counts towards the } \\
\text { total number of servings per day }\end{array}$ & $\begin{array}{l}\text { Only } 1 \text { serving of juice or } 1 \text { serving of dried fruit } \\
\text { counted }\end{array}$ \\
\hline $\begin{array}{l}\text { Breads and } \\
\text { cereals }\end{array}$ & $\begin{array}{l}\text { Breads and cereals } \\
\text { (including breakfast, } \\
\text { cereals, breads, grains, } \\
\text { rice and pasta), } \\
\text { preferably wholegrain }\end{array}$ & $\begin{array}{l}\text { At least } 6 \text { servings/d (choose } \\
\text { wholegrain breads and cereals) }\end{array}$ & $\begin{array}{l}\text { Cakes and biscuits not included } \\
\text { For analyses of healthier breads and cereals, } \\
\text { only high-fibre white, brown, wholemeal and } \\
\text { wholegrain breads included and only high- } \\
\text { fibre cereals, muesli, porridge, weetbix and } \\
\text { bran flakes included }\end{array}$ \\
\hline $\begin{array}{l}\text { Milk and milk } \\
\text { products }\end{array}$ & $\begin{array}{l}\text { Milk and milk products } \\
\text { (includes milk, cheese, } \\
\text { yoghurt and ice cream) } \\
\text { and alternatives }\end{array}$ & $\begin{array}{l}\text { At least } 3 \text { servings/d (choose low- } \\
\text { or reduced-fat options) }\end{array}$ & $\begin{array}{l}\text { For analyses of healthier milk and milk products, } \\
\text { only reduced-fat and skimmed/trim milk } \\
\text { included }\end{array}$ \\
\hline $\begin{array}{l}\text { Lean meat, meat } \\
\text { alternatives } \\
\text { and eggs }\end{array}$ & $\begin{array}{l}\text { Lean meat, poultry, } \\
\text { seafood, eggs, nuts and } \\
\text { seeds, and legumes }\end{array}$ & At least 2 servings/d & $\begin{array}{l}\text { Does not include chicken nuggets or chicken } \\
\text { roll, processed meats, battered or fried fish, } \\
\text { food prepared in fast-food outlets }\end{array}$ \\
\hline
\end{tabular}

*French fries are long thinly cut slices of potato that are fried, whereas hot chips are more thickly sliced. Kumara is New Zealand's native potato. 
bread; high-fibre cereals, muesli, porridge, weetbix and bran flakes). Similarly we reported both the total number of daily servings of milk and milk products and of healthier milk and milk products (reduced-fat or skimmed/trim milk).

We asked the pregnant women to describe the frequency of their intake of foods likely to be high in fats, sugars and/ or salt (see online supplementary material, Supplementary Table 1$)^{(11)}$. The recommendations for consumption of these foods during pregnancy are identical to the Ministry of Health guideline statements for healthy adults ${ }^{(11,20)}$. We also asked open-ended questions about foods and drinks the women deliberately avoided during pregnancy to assess adherence to recommendations that seek to reduce the risk of listeriosis (Supplementary Table 1) ${ }^{(11)}$.

Question formatting was consistent with that used in the dietary history questionnaire component of the 2008/2009 NZ Adult National Nutrition Survey ${ }^{(21)}$. Show cards with pictures of standard serving sizes were used to assist description of portion size consumed. Allowing portion size to be described has been shown to increase the agreement between FFQ and reference dietary measures ${ }^{(22)}$. Frequency categories were used in increasing order: not at all, less than once per month and number of times per month, week or day.

Interviewers received comprehensive training in the FFQ administration. Content and delivery of the FFQ (as part of the entire antenatal interview) were refined during piloting with an ethnically diverse group of 200 pregnant women enrolled approximately 6 months earlier and from the same geographical area as the main cohort ${ }^{(23)}$.

For the analyses presented here, ethnicity was defined as the mother's self-prioritised ethnicity. The self-prioritised ethnicities were gathered from participants at the most detailed level possible and were then coded into six Level 1 categories following Statistics New Zealand's coding criteria: (i) European; (ii) Māori; (iii) Pacific Peoples; (iv) Asian; (v) Middle Eastern; Latin American and African; and (vi) other ${ }^{(24)}$. Parental socio-economic status, educational qualifications and household income items were based on measures taken from Statistics New Zealand's 2006 national census and 2008 General Social Survey ${ }^{(25,26)}$. The measures are among those included in the Core Questions module, a set of questions designed to allow comparability across social surveys ${ }^{(27)}$.

Area-level socio-economic deprivation was measured using the NZ Index of Deprivation (NZDep06), grouped as quintiles ${ }^{(28,29)}$. NZDep06 is derived from 2006 census data on nine socio-economic characteristics (means-tested benefits, employment, household income, access to a telephone, access to a car, single-parent family, qualifications, home ownership, household overcrowding) at aggregations of approximately 100 people and assigned to individual observations based on geo-coded address data.

Descriptive statistics were used to investigate adherence to the recommendations on frequency of consumption of: (i) vegetables and fruit; (ii) breads and cereals; (iii) milk and milk products; and (iv) lean meat, meat alternatives (nuts and seeds, and legumes) and eggs. In the analyses we did not include processed foods such as cakes and biscuits, fruit juice, processed meats or hot chips.

Associations of maternal ethnicity, age at pregnancy, education and area-level socio-economic deprivation with adherence to food group recommendations were described. Proportions were compared using the $\chi^{2}$ test and, for ordinallevel variables, the $\chi^{2}$ test for trend. Logistic regression models were then developed to examine the likelihood of women adhering to the nutritional recommendations during pregnancy. Each recommendation was modelled separately with maternal ethnicity, age and education, with parity and pregnancy planning, and with household income and socioeconomic deprivation. The reference group for household income was \$NZ 70001-100000 because the median household gross income in NZ in 2010 was $\$ \mathrm{NZ} 75700^{(30)}$. All analyses were conducted using the SAS statistical software package version 9.2. A two-sided $P$ value of $<0.05$ was considered statistically significant.

\section{Results}

Of the 5664 respondents, information on the expected due date was available for 5584 . For these 5584 respondents the mean gestational age at the time of interview was 31 (sD 4) weeks. Most ( $n$ 4365, 78\%) were interviewed during the third trimester (weeks 28 to birth). Cohort births occurred from March 2009 to May 2010.

The self-prioritised ethnicity breakdown was $56 \%$ European, 13\% Māori, $13 \%$ Pacific, 14\% Asian and 4\% other ethnicities. The median (range) age was 31 (15-47) years, $70 \%$ had tertiary education, $58 \%$ had older children, $62 \%$ had a planned pregnancy and $26 \%$ lived in households within the most deprived areas (deciles 9 and 10).

\section{Food group consumption during pregnancy}

Consumption of food groups during pregnancy is shown in Table 2. The number of daily servings of vegetables consumed during pregnancy was evenly distributed across 1,2 , 3 or $\geq 4$ servings, with a smaller proportion ( $7 \%$ ) having $<1$ serving of vegetables/d. The number of daily servings of fruit showed similarly wide variance but with a larger proportion (43\%) consuming $\geq 4$ servings/d. Almost all (99\%) of the pregnant women consumed breads and cereals on a daily basis, with $68 \%$ of women consuming healthier breads and cereals on a daily basis. Milk and milk products were also consumed on a daily basis by almost all (96\%) and healthier milk and milk products on a daily basis by $42 \%$. Most (79\%) of the women consumed servings of lean meat, meat alternatives or eggs no more frequently than once daily.

\section{Consumption of foods likely to be high in fats, sugars and/or salt}

Table 3 shows consumption of foods likely to be high in fats, sugars and/or salt. Fried potatoes including kumara, NZ's native potato, were consumed at least weekly by 


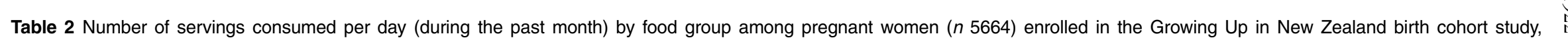
2009-2010

\begin{tabular}{|c|c|c|c|c|c|c|c|c|c|c|c|c|c|c|c|c|}
\hline \multirow[b]{3}{*}{ Food group } & \multicolumn{16}{|c|}{ Number of servings per day } \\
\hline & \multicolumn{2}{|r|}{$\geq 6$} & \multicolumn{2}{|r|}{5} & \multicolumn{2}{|c|}{4 or $\geq 4$} & \multicolumn{2}{|c|}{3} & \multicolumn{2}{|c|}{2} & \multicolumn{2}{|c|}{1} & \multicolumn{2}{|c|}{$<1$} & \multicolumn{2}{|c|}{ None $^{*}$} \\
\hline & $n$ & row $\%$ & $n$ & row $\%$ & $n$ & row $\%$ & $n$ & row $\%$ & $n$ & row $\%$ & $n$ & row $\%$ & $n$ & row \% & $n$ & row \% \\
\hline Vegetables† & & $--^{\star \star}$ & & $--^{\star \star}$ & 1546 & 27 & 1242 & 22 & 1258 & 22 & 1217 & 22 & 385 & 7 & 15 & 0 \\
\hline Fruit & & $-^{\star \star}$ & & $-^{\star \star *}$ & 2411 & 43 & 1182 & 21 & 1021 & 18 & 744 & 13 & 293 & 5 & 13 & 0 \\
\hline Breads and cereals $\ddagger$ & 1489 & 26 & 784 & 14 & 1027 & 18 & 1073 & 19 & 875 & 16 & 360 & 6 & 52 & 1 & 4 & 0 \\
\hline Healthier breads and cereals $\S$ & 1115 & 20 & 20 & 0 & 1185 & 21 & 6 & 1 & 596 & 11 & 847 & 15 & 504 & 9 & 1333 & 24 \\
\hline Milk and milk products & & $-^{\star *}$ & & $-^{\star \star}$ & 2036 & 36 & 1238 & 22 & 1307 & 23 & 867 & 15 & 193 & 3 & 23 & 1 \\
\hline Healthier milk and milk products\|l & & $-{ }^{* *}$ & & $-^{\star \star}$ & 226 & 4 & 329 & 6 & 857 & 15 & 990 & 17 & 552 & 10 & 2710 & 48 \\
\hline 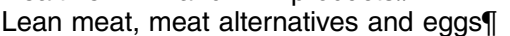 & & $-{ }^{\star \star}$ & & $-^{\star \star}$ & 242 & 4 & 245 & 4 & 739 & 13 & 2864 & 51 & 1533 & 27 & 39 & 1 \\
\hline
\end{tabular}

${ }^{*}$ None $=$ not in the past 4 weeks.

Does not include hot chips, French fries, wedges or kumara chips.

tDoes not include cakes and biscuits.

§Breads: high-fibre white, brown bread, wholemeal, wholegrain; cereals: high-fibre cereals, muesli, porridge, weetbix, bran flakes.

IIMilk: reduced-fat or skimmed/trim milk.

ףDoes not include chicken nuggets or chicken roll, processed meats, battered or fried fish, food prepared in fast-food outlets.

${ }^{* *}$ Most frequent category asked was $4+$ per day.

Table 3 Consumption of foods and beverages (during the past month) likely to be high in fats, sugars and/or salt among pregnant women ( $n$ 5664) enrolled in the Growing Up in New Zealand birth cohort study, 2009-2010

\begin{tabular}{|c|c|c|c|c|c|c|c|c|c|c|c|c|c|c|c|c|}
\hline \multirow[b]{3}{*}{ Type of food or beverage } & \multicolumn{4}{|c|}{ Servings per day } & \multicolumn{6}{|c|}{ Servings per week } & \multicolumn{4}{|c|}{ Servings per month } & & \\
\hline & \multicolumn{2}{|r|}{2} & \multicolumn{2}{|c|}{1} & \multicolumn{2}{|c|}{$5-6$} & \multicolumn{2}{|c|}{$3-4$} & \multicolumn{2}{|c|}{$1-2$} & \multicolumn{2}{|c|}{$2-3$} & \multicolumn{2}{|r|}{1} & \multicolumn{2}{|c|}{ None $^{*}$} \\
\hline & $n$ & row \% & $n$ & row \% & $n$ & row \% & $n$ & row \% & $n$ & row $\%$ & $n$ & row \% & $n$ & row $\%$ & $n$ & row $\%$ \\
\hline Hot chips, French fries, wedges or kumara chips & 67 & 1 & 139 & 3 & 79 & 1 & 334 & 6 & 2529 & 45 & 1182 & 21 & 573 & 10 & 758 & 13 \\
\hline Battered or fried fish or seafood & 16 & 0 & 30 & 1 & 12 & 0 & 53 & 1 & 716 & 13 & 873 & 15 & 802 & 14 & 3150 & 56 \\
\hline Processed meats $\dagger$ & 39 & 1 & 157 & 3 & 66 & 1 & 340 & 6 & 2004 & 35 & 878 & 16 & 290 & 5 & 1880 & 33 \\
\hline Takeawaysł & 35 & 1 & 54 & 1 & 46 & 1 & 246 & 4 & 1749 & 31 & 1486 & 26 & 816 & 14 & 1224 & 22 \\
\hline Soft drinks or energy drinks§ & 239 & 4 & 311 & 6 & 128 & 2 & 482 & 9 & 1073 & 19 & 562 & 10 & 253 & 4 & 2610 & 46 \\
\hline Soft drinks that don't contain sugar (diet varieties) & 67 & 1 & 144 & 3 & 75 & 1 & 160 & 3 & 376 & 7 & 150 & 3 & 85 & 1 & 4599 & 81 \\
\hline Confectionery, lollies, sweets and chocolate & 331 & 6 & 780 & 14 & 400 & 7 & 1126 & 20 & 1663 & 29 & 411 & 7 & 129 & 2 & 819 & 15 \\
\hline Snacks (crisps, nuts) & 147 & 3 & 371 & 7 & 231 & 4 & 818 & 14 & 2061 & 36 & 740 & 13 & 253 & 5 & 1036 & 18 \\
\hline
\end{tabular}

${ }^{*}$ None $=$ not in the past 4 weeks.

Processed meats includes ham, bacon, pastrami, salami, luncheon meat and canned corn beef.

Takeaways includes foods from fast-food outlets

$\S$ Soft drinks include carbonated beverages and energy drinks. 
$56 \%$ of the pregnant women; battered or fried fish or seafood by $15 \%$; processed meats by $46 \%$; and takeaways by $38 \%$. Soft drinks or energy drinks were consumed at least weekly by $40 \%$ and at least daily by $10 \%$. Seventy-six per cent of the women consumed confectionery, lollies, sweets and chocolate at least weekly and $20 \%$ consumed these daily. Snacks such as crisps and nuts were consumed at least weekly by $64 \%$ and daily by $10 \%$.

\section{Avoidance of foods}

As shown in Table 4, specific food or drinks were deliberately avoided by $87 \%$ of the pregnant women. These included foods that the Ministry of Health recommended that pregnant women avoid.

\section{Adherence to recommendations for main food groups}

The recommended number of daily servings of vegetables and fruit $(\geq 6)$ were met by $25 \%$ of the pregnant women, with $27 \%$ meeting the recommendations for vegetables ( $\geq 4$ servings/d) and $82 \%$ for fruit ( $\geq 2$ servings/d). The recommended number of daily servings of bread and cereals $(\geq 6)$ were consumed by $26 \%$ of the women, of milk and milk products ( $\geq 3$ servings/d) by $58 \%$ and of lean meat, meat alternatives or eggs ( $\geq 2$ servings/d) by $21 \%$. Overall, $24 \%$ ( $n$ 1347) of the pregnant women did not meet any of the Ministry of Health recommendations, while $38 \%$ ( $n$ 2144) met one, $25 \%$ ( $n$ 1437) met two, $10 \%$ ( $n$ 577) met three and $3 \%(n$ 159) met all four food group serving recommendations.

Figure 1 shows the percentage of pregnant women meeting the food group serving recommendations by ethnicity, age, education and socio-economic deprivation. In unadjusted analyses, adherence to the recommendations varied by all four of these variables. Adherence varied by ethnicity for breads/cereals $(P<0 \cdot 001)$, milk/milk products $(P<0.001)$ and meat/eggs groups $(P<0.001$; Fig. 1(a) $)$. Adherence varied by age for the vegetables/fruit $(P<0.001)$, breads/cereals $(P<0.001)$ and meat/eggs groups $(P<0.001$; Fig. 1(b)). Adherence varied with maternal education for all four food groups $(P<0.001$ for vegetables/fruit, breads/cereals and meat/eggs groups; $P=0.005$ for milk/milk products; Fig. 1(c)). Adherence varied with area-level deprivation for vegetables/fruit $(P=0.009)$, breads/cereals $(P<0.001)$ and meat/eggs groups $(P<0 \cdot 001)$.

\section{Multivariate analysis of adherence for the four main food groups}

Table 5 presents the results of multivariate analysis of adherence for the four main food groups by maternal characteristics.

\section{Vegetables and fruit}

Maternal age was the only variable independently associated with adherence to the recommendations for the vegetables/fruit group. In comparison with pregnant women aged 30-39 years, women were less likely to meet the recommendations if they were less than 20 years old $(\mathrm{OR}=0 \cdot 5)$ or $20-29$ years old $(\mathrm{OR}=0 \cdot 7)$.

\section{Breads and cereals}

Adherence to recommendations for the breads/cereals group varied with maternal ethnicity, age, parity and education and with household income. Māori women $(\mathrm{OR}=2 \cdot 2)$ and Pacific women ( $\mathrm{OR}=2 \cdot 6)$ were more likely than European women to be adherent. Women less than 20 years old $(\mathrm{OR}=1 \cdot 7)$ were more likely to meet the recommendations than women aged 30-39 years. Women with older children $(\mathrm{OR}=1.7)$ were more likely to meet the recommendations than women for whom this was their first child. Women with only primary education $(\mathrm{OR}=1.5)$ were more likely to meet the recommendations than women with tertiary education. Adherence to the recommendations varied inversely with household income. In comparison with households with an annual income of \$NZ 70 001-100 000, pregnant women living in households with an annual income greater than \$NZ 150000 were less likely $(\mathrm{OR}=0.7)$ and those living in a household with an annual income of $\$ \mathrm{NZ} 30000-50000(\mathrm{OR}=1 \cdot 3)$ were more likely to meet the recommendations.

When the multiple variable analyses were limited to healthier breads and cereals, adherence to recommendations varied with maternal ethnicity, age and pregnancy planning (see online supplementary material, Supplementary Table 2). Associations with parity, maternal education and household income were no longer apparent. Māori women $(\mathrm{OR}=1 \cdot 3)$ were more likely and women of Asian ( $\mathrm{OR}=0.4)$ and other ( $\mathrm{OR}=0.5)$ ethnic groups were less likely than European women to be adherent. Women aged $20-29$ years were less likely $(\mathrm{OR}=0.8)$ and women 40 years and older were more likely $(\mathrm{OR}=1.4)$ to meet recommendations than women aged 30-39 years. Women whose pregnancy was unplanned were less likely $(\mathrm{OR}=$ $0 \cdot 8$ ) to meet recommendations.

\section{Milk and milk products}

Recommendation adherence for the milk/milk products group varied with ethnicity and household income. Pregnant Pacific $(\mathrm{OR}=0.8)$ and Asian $(\mathrm{OR}=0.5)$ women were less likely than European women to meet the recommendations for the milk/milk products group. In comparison with households with an annual income of $\$ \mathrm{NZ}$ 70001-100000, women living in households with an annual income of $\$ \mathrm{NZ} 30001-50000$ were less likely to meet the recommendations $(\mathrm{OR}=0 \cdot 7)$.

When the multiple variable analyses were limited to healthier milks and milk products, adherence to recommendations still varied with maternal ethnicity and household income and also with parity. Pregnant Asian (OR $=0 \cdot 3$ ) women were less likely than European women to meet the recommendations for the milk/milk products group. In comparison with households with an annual income of 
Table 4 Foods that were avoided during pregnancy among pregnant women ( $n$ 5664) enrolled in the Growing Up in New Zealand birth cohort study, 2009-2010

\begin{tabular}{lrr}
\hline Food description & Number who avoided this food \\
\hline Raw, smoked or pre-cooked fish, seafood products chilled or frozen & 2209 \\
Ham and other pre-cooked meat products & 1758 \\
Soft pasteurised cheese (brie, camembert, blue, ricotta, mozzarella, feta) & 2535 & 45 \\
Stored salads and coleslaw & 1454 & 35 \\
Sushi & 837 & 31 \\
Raw eggs & 327 & 29 \\
Cold pre-cooked chicken & 257 & 7 \\
Pâté & 127 & 91 \\
Raw unpasteurised milk and milk products & 62 & 3 \\
Hummus & 27 \\
Marinated mussels or surimi & 2 \\
\hline
\end{tabular}

\$NZ 70 001-100 000, pregnant women living in households with an annual income less than \$NZ 20000 were less likely to meet the recommendations $(\mathrm{OR}=0 \cdot 4)$. Women with older children $(\mathrm{OR}=0 \cdot 8)$ were less likely to meet recommendations.

\section{Lean meat, meat alternatives and eggs}

Adherence varied with ethnicity, pregnancy planning and household income. In comparison with pregnant European women, pregnant Māori $(\mathrm{OR}=1 \cdot 8)$, Pacific $(\mathrm{OR}=3 \cdot 1)$ and Asian $(\mathrm{OR}=3 \cdot 8)$ women and pregnant women of other ethnic groups (OR 1.6) were more likely to meet the recommendations. Women whose pregnancy was unplanned were more likely to meet the recommendations $(\mathrm{OR}=1 \cdot 3)$ than those for whom the pregnancy was planned. Women living in the two lowest household income groups ( $<$ \$NZ 20001 , $\mathrm{OR}=1 \cdot 6 ; \quad \$ N Z$ 20001-30000, OR=1.3) were more likely to be adherent to the meat/eggs recommendations compared with pregnant women in the median income group (\$NZ 70 001-100 000).

When season of enrolment was included in the multiple variable analyses, the significant associations of maternal characteristics with nutritional guideline adherence shown in Table 5 were unchanged. Season of enrolment was not independently associated with adherence for vegetables and fruit $(P=0 \cdot 16)$, breads and cereals $(P=0.45)$ or lean meat, meat alternatives and eggs $(P=0.75)$ but was for milk and milk products $(P=0.003)$. In comparison with those enrolled in summer, enrolment in autumn was associated with increased odds of adherence with the recommended number of servings of milk and milk products $(\mathrm{OR}=1 \cdot 23 ; 95 \% \mathrm{CI} 1 \cdot 01,1 \cdot 51)$.

\section{Discussion}

In this nationally representative sample of pregnant NZ women, the average number of daily servings of vegetables and fruit, and breads and cereals varied widely. Less variability was present in daily servings of milk and milk products and of meat, meat alternatives and eggs.

For three of the four main food groups (vegetables/fruit, breads/cereals and meat/eggs), less than $30 \%$ of the women met the Ministry of Health recommendations. The milk/milk products group was the only food group for which more than half ( $58 \%$ ) of the women met recommendations; however, for only $10 \%$ of women was this recommendation met by the consumption of healthier milk and milk products. Within the vegetables/fruit group a larger proportion of the women met the recommendations for fruit (82\%) than they did for vegetables (27\%). One in four $(24 \%)$ of the women met none of the four food group recommendations and only $3 \%$ met the recommendations for all four food groups.

The pregnant women consumed foods likely to be high in fats, sugars and/or salt at a frequency that exceeds the admittedly imprecise recommendations that these only be consumed 'occasionally'. Most women demonstrated awareness of the recommendations to avoid certain foods during pregnancy (e.g. raw seafood) presumably because they were aware of the potential for such foods to compromise their health and the health of their fetus. However, less than half of the women avoided each individual risky food group. As has been shown in other countries, awareness of listeriosis and the foods in which it can be found is relatively poor in $\mathrm{NZ}^{(31)}$. A survey of pregnant women conducted within the region from which our cohort was recruited showed that only one in four (26\%) women were able to correctly identify all of the common foods that should be avoided ${ }^{(32)}$.

The current study is the largest one of dietary intake in pregnancy in NZ. The size of our cohort was determined by the need to have adequate explanatory power for analyses to be performed within the main ethnic and socio-economic population subgroups in $\mathrm{NZ}^{(18)}$. Thus in multiple variable analyses we were able to demonstrate statistical significance for an odds ratio as small as 1.3 , i.e. a $30 \%$ difference between population subgroups in adherence to a dietary recommendation. Differences of this size are of both clinical and public health significance ${ }^{(33)}$.

The only other surveys that have population-specific dietary data are the National Nutrition Surveys. The most recent of these was a voluntary cross-sectional survey of 4721 New Zealanders aged 15 years and over ${ }^{(5)}$. Comparable questions were used to report intakes of vegetables and fruit. Fifty-six per cent of women aged 19-30 years consumed 

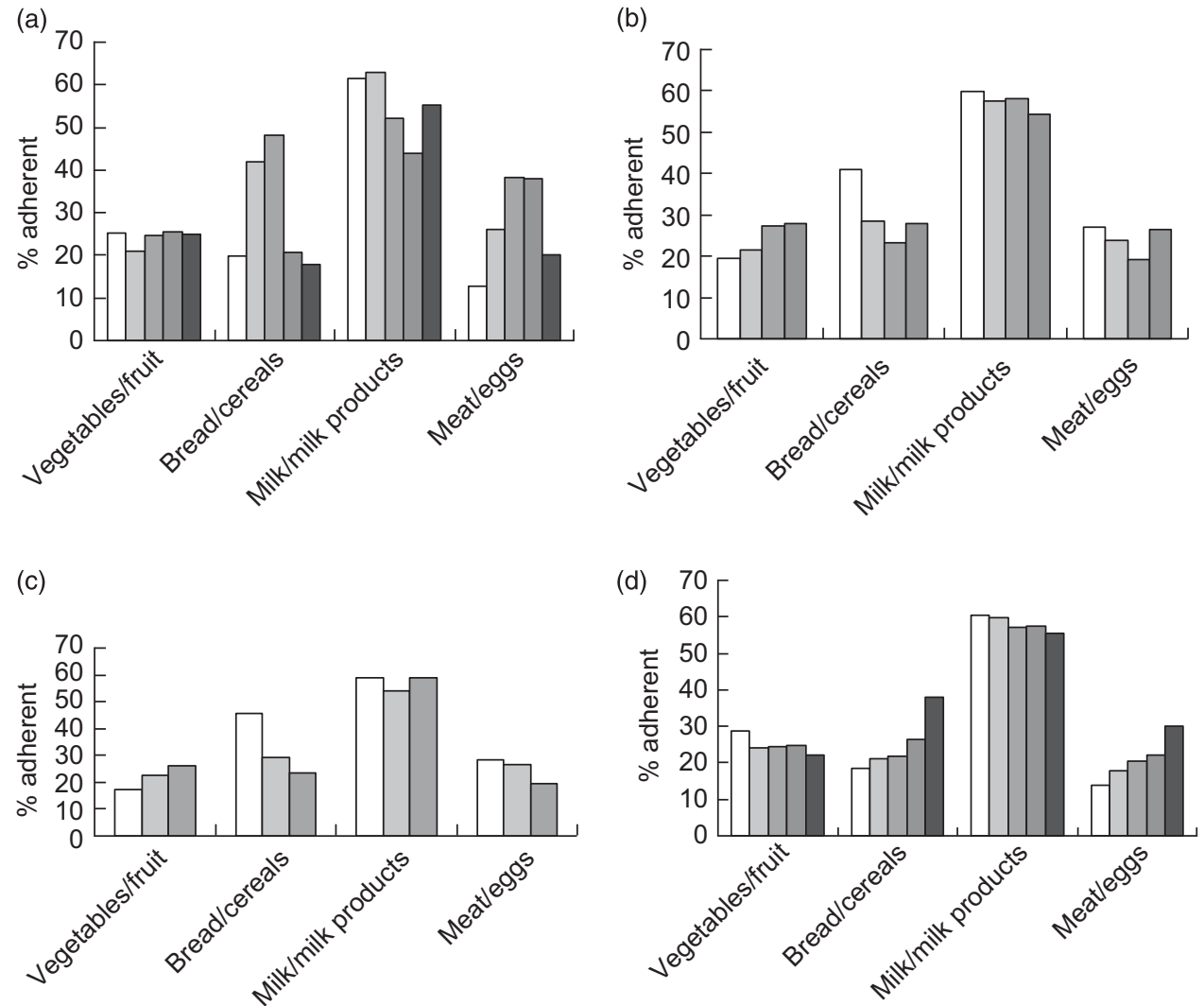

Fig. 1 Adherence to the New Zealand Ministry of Health nutritional guidelines in pregnancy by maternal demographics among pregnant women ( $n$ 5664) enrolled in the Growing Up in New Zealand birth cohort study, 2009-2010. (a) Adherence by maternal ethnic group ( $\square$, European; $\square$, Māori; $\square$, Pacific Peoples; $\square$, Asian; $\square$, other). Ethnic group associations within food groups as follows. Vegetables/fruit group: none $(P$ trend $=0.18)$; breads/cereals group: in comparison with European women, a larger proportion of Māori (42\% v. $20 \%)$ and Pacific (48\% v. $20 \%)$ women were adherent $(P$ trend $<0.001)$; milk/milk products group: adherence $>50 \%$ for all ethnic groups (European $62 \%$, Māori $63 \%$, Pacific $52 \%$, other $55 \%$ ) except Asian (44\%; $P$ trend $<0.001$ ); meat/eggs group: in comparison with European women, a larger proportion of Pacific (38\% v. $13 \%)$ and Asian $(38 \%$ v. $13 \%)$ women were adherent $(P$ trend $<0.001)$. (b) Adherence by maternal age group $(\square,<20$ years; $\square, 20-29$ years; $\square$, 30-39 years; $\square, 40+$ years). Age group associations within food groups as follows. Vegetables/fruit group: adherence increased with increasing age $(P$ trend $<0.001)$; breads/cereals group: adherence highest in those $<20$ years old $(41 \%)$ and lowest in those aged $30-39$ years (23\%; $P$ trend $<0.001)$; milk/milk products group: none $(P$ trend $=0.66)$; meat/eggs group: adherence lower in those aged $30-39$ years (19\%) than in younger $(<20$ years $27 \%, 20-29$ years $24 \%)$ or older $(40+$ years $27 \%)$ age groups $(P$ trend $<0.001)$. (c) Adherence by maternal education ( $\square$, primary; $\square$, secondary; $\square$, tertiary). Educational group associations within food groups as follows. Vegetables/fruit group: adherence increased with increasing education $(P$ trend $<0.001)$; breads/cereals group: adherence decreased with increasing education $(P$ trend $<0.001)$; milk/milk products group: for all levels of maternal education recommendations were met by $>50 \%$ of the pregnant women $(P$ trend $=0.005)$; meat/eggs group: adherence decreased with increasing education $(P$ trend $<0.001)$. (d) Adherence by area-level socio-economic deprivation, measured using the NZ Index of Deprivation (NZDep06), grouped as quintiles ${ }^{(28,29)}(\square$, Dep 1-2 (least deprived); $\square$, Dep 3-4; $\square$, Dep 5-6; $\square$, Dep 7-8; $\square$, Dep 9-10 (most deprived)). Socio-economic deprivation associations within food groups as follows. Vegetables/fruit group: adherence decreased with increasing household deprivation $(P$ trend $=0.009)$; breads/cereals group: adherence increased with increasing household deprivation $(P$ trend $<0.001)$; milk/milk products group: none $(P$ trend $=0.11)$; meat/eggs group: adherence increased with increasing household deprivation $(P$ trend $<0.001) . P$ trend determined using the $\chi^{2}$ test for trend

three or more servings of vegetables daily, compared with $49 \%$ in the present study, and $61 \%$ consumed two or more servings of fruit daily, compared with $81 \%$ in the present study ${ }^{(5)}$. Thus, we believe that the poor adherence with dietary recommendations during pregnancy was likely to be present before these women became pregnant.

Assessment of diet was only one component of this antenatal interview which gathered information on the broad range of factors of relevance to the subsequent health of the child cohort. Hence it was necessary to limit the size of our FFQ to forty-four items. For an analysis of adherence to dietary recommendations, we believe this FFQ was sufficiently detailed. Maternal dietary pattern assessment using a twenty-item FFQ was recently shown to correlate highly $(r=0.94)$ with the original 100-item FFQ used in the Southampton Women's Survey ${ }^{(34)}$.

That pregnant women in NZ appear no more adherent to dietary recommendations than non-pregnant women is consistent with recent data from Australia which show that neither being pregnant nor planning to become pregnant 
Table 5 Adherence to the New Zealand Ministry of Health nutritional guidelines in pregnancy by maternal characteristics among pregnant women ( $n$ 5664) enrolled in the Growing Up in New Zealand birth cohort study, 2009-2010

\begin{tabular}{|c|c|c|c|c|c|c|c|c|c|}
\hline \multirow[b]{3}{*}{ Maternal characteristic } & \multicolumn{9}{|c|}{ Food groups } \\
\hline & \multicolumn{2}{|c|}{ Vegetables and fruit ${ }^{*}$} & \multicolumn{2}{|c|}{ Breads and cereals $†$} & \multicolumn{2}{|c|}{ Milk and milk products } & \multicolumn{3}{|c|}{ Lean meat, meat alternatives and eggs } \\
\hline & OR§ & $95 \% \mathrm{Cl}$ & OR§ & $95 \% \mathrm{Cl}$ & OR§ & $95 \% \mathrm{Cl}$ & OR§ & & $95 \% \mathrm{Cl}$ \\
\hline \multicolumn{10}{|l|}{ Self-prioritised ethnicityll } \\
\hline European & \multicolumn{2}{|c|}{1.0} & \multicolumn{2}{|c|}{1.0} & \multicolumn{2}{|c|}{1.0} & \multicolumn{3}{|c|}{1.0} \\
\hline Māori & 1.0 & $0.8,1 \cdot 2$ & $2 \cdot 2$ & $1 \cdot 8,2 \cdot 7$ & $1 \cdot 1$ & $0.9,1.3$ & $1 \cdot 8$ & & $1 \cdot 5,2 \cdot 4$ \\
\hline Pacific peoples & $1 \cdot 2$ & $1.0,1 \cdot 6$ & 2.6 & $2 \cdot 1,3 \cdot 3$ & 0.8 & $0.6,0.9$ & $3 \cdot 1$ & & $2 \cdot 5,4.0$ \\
\hline Asian & $1 \cdot 1$ & $0.9,1.4$ & 1.0 & $0.8,1 \cdot 2$ & 0.5 & $0.4,0.6$ & 3.8 & & $3 \cdot 1,4 \cdot 7$ \\
\hline Other & $1 \cdot 1$ & $0.7,1.5$ & 0.7 & $0.5,1.1$ & 0.8 & $0.6,1.2$ & $1 \cdot 6$ & & $1 \cdot 0,2 \cdot 3$ \\
\hline & \multicolumn{2}{|c|}{$P=0.38$} & \multicolumn{2}{|c|}{$P<0.001$} & \multicolumn{2}{|c|}{$P<0.001$} & \multicolumn{3}{|c|}{$P<0.001$} \\
\hline \multicolumn{10}{|l|}{ Age group } \\
\hline$<20$ years & 0.5 & $0.3,0.9$ & 1.7 & $1 \cdot 1,2 \cdot 5$ & $1 \cdot 1$ & $0.7,1.6$ & 1.0 & & $0.6,1.5$ \\
\hline $20-29$ years & 0.7 & $0.6,0.9$ & $1 \cdot 0$ & $0.9,1.2$ & $1 \cdot 1$ & $0.9,1.2$ & 0.9 & & $0.7,1.0$ \\
\hline 30-39 years & \multicolumn{2}{|c|}{1.0} & \multicolumn{2}{|c|}{1.0} & \multicolumn{2}{|c|}{1.0} & \multicolumn{3}{|c|}{1.0} \\
\hline $40+$ years & \multicolumn{2}{|c|}{$P=0.001$} & \multicolumn{2}{|c|}{$P=0.048$} & \multicolumn{2}{|c|}{$P=0.29$} & \multicolumn{3}{|c|}{$P=0.07$} \\
\hline Parity & & & & & & & & & \\
\hline First child & & 0 & & 1.0 & & & & 1.0 & \\
\hline Subsequent child & 0.9 & $\begin{array}{l}0.8,1.0 \\
0.07\end{array}$ & ${ }^{1.7} P$ & $\begin{array}{l}1.4,2 \cdot 0 \\
0.001\end{array}$ & 1.0 & $\begin{array}{l}0.9,1.1 \\
0.96\end{array}$ & 1.0 & $P=0.95$ & $0.8,1 \cdot 2$ \\
\hline Pregnancy planning & & & & & & & & & \\
\hline Planned & & 0 & & 1.0 & & 0 & & 1.0 & \\
\hline Unplanned & ${ }^{1.0}$ & $\begin{array}{l}0.9,1.2 \\
0.77\end{array}$ & ${ }^{1.0} F$ & $\begin{array}{l}0.9,1.2 \\
0.83\end{array}$ & $1 \cdot 1$ & $\begin{array}{l}0.9,1 \cdot 2 \\
0.39\end{array}$ & 1.3 & $P=0.003$ & $1 \cdot 1,1 \cdot 5$ \\
\hline Education & & & & & & & & & \\
\hline Primary & 0.8 & $0.6,1.2$ & 1.5 & $1 \cdot 1,2 \cdot 0$ & $1 \cdot 1$ & $0.8,1.5$ & $1 \cdot 2$ & & $0.9,1.7$ \\
\hline Secondary & 0.9 & $0.8,1 \cdot 1$ & 0.9 & $0.7,1.0$ & 0.9 & $0.7,1.0$ & $1 \cdot 2$ & & $1.0,1.4$ \\
\hline Tertiary & & $\begin{array}{l}.0 \\
0.35\end{array}$ & & $\begin{array}{l}1.0 \\
0.004\end{array}$ & & $\begin{array}{l}0 \\
0.06\end{array}$ & & $\begin{array}{c}1.0 \\
P=0.20\end{array}$ & \\
\hline Household income ( $\$ N Z$ & & & & & & & & & \\
\hline$<20000$ & 0.8 & $0.5,1 \cdot 2$ & $1 \cdot 3$ & $0.9,1.8$ & 0.9 & $0.6,1.2$ & $1 \cdot 6$ & & $1 \cdot 1,2 \cdot 2$ \\
\hline $20001-30000$ & 0.9 & $0.7,1.3$ & 1.3 & $0.9,1.8$ & 0.8 & $0.6,1.1$ & 1.3 & & $1 \cdot 0,1 \cdot 8$ \\
\hline $30001-50000$ & 0.9 & $0.7,1 \cdot 2$ & $1 \cdot 3$ & $1 \cdot 0,1 \cdot 6$ & 0.7 & $0.6,0.9$ & $1 \cdot 1$ & & $0.9,1.4$ \\
\hline $50001-70000$ & 0.9 & $0 \cdot 7,1 \cdot 1$ & $1 \cdot 1$ & $0.9,1.4$ & 0.9 & $0.7,1 \cdot 1$ & 0.9 & & $0.7,1 \cdot 1$ \\
\hline $70001-100000$ & & 0 & & 1.0 & & 0 & & 1.0 & \\
\hline $100001-150000$ & 1.0 & $0.8,1.3$ & 0.9 & $0.7,1 \cdot 1$ & 1. & $0.9,1.3$ & 0.8 & & $0.6,1 \cdot 0$ \\
\hline$>150000$ & 1.0 & $0.9,1.3$ & 0.7 & $0.6,0.9$ & 0.9 & $0.8,1.1$ & 0.8 & & $0.7,1 \cdot 1$ \\
\hline & & 0.83 & & 0.001 & & .009 & & $P=0.004$ & \\
\hline Socio-economic deprivat & tionף & & & & & & & & \\
\hline 1-2 (least deprived) & 1.2 & $1.0,1.5$ & 0.8 & $0.6,1.0$ & 1.0 & $0.8,1.3$ & 0.9 & & $0.6,1 \cdot 1$ \\
\hline $3-4$ & 1.0 & $0.8,1.2$ & 0.9 & $0.7,1.1$ & $1 \cdot 0$ & $0.8,1.2$ & 1.0 & & $0.8,1.3$ \\
\hline $5-6$ & 1.0 & $0.8,1.3$ & 0.8 & $0.6,1.0$ & 0.9 & $0.8,1 \cdot 1$ & $1 \cdot 1$ & & $0.8,1.3$ \\
\hline $7-8$ & $1 \cdot 1$ & $0.9,1 \cdot 3$ & 0.9 & $0.7,1 \cdot 1$ & $1 \cdot 0$ & $0.9,1.2$ & 0.9 & & $0.7,1 \cdot 1$ \\
\hline 9-10 (most deprived) & & $\begin{array}{l}0 \\
0.21\end{array}$ & & $\begin{array}{l}1.0 \\
0.30\end{array}$ & & $\begin{array}{l}0 \\
0.84\end{array}$ & & $\begin{array}{c}1.0 \\
P=0.36\end{array}$ & \\
\hline
\end{tabular}

${ }^{*}$ Does not include hot chips, French fries, wedges or kumara chips.

tDoes not include cakes and biscuits.

fDoes not include chicken nuggets or chicken roll, processed meats, battered or fried fish, food prepared in fast-food outlets.

§Odds ratios are adjusted for all the other variables in the table.

IIExternal prioritisation was used for the approximately $4 \%$ of mothers with more than one ethnicity.

IArea-level socio-economic deprivation was measured using the NZ Index of Deprivation (NZDep06), grouped as quintiles ${ }^{(28,29)}$.

was predictive of diet quality ${ }^{(35)}$. Data from the Southampton Women's Survey, which established a pre-birth cohort, also showed that women's diets during the first and third trimesters of pregnancy showed little change in comparison with their pre-pregnancy diet ${ }^{(36)}$.

The low level of adherence with dietary recommendations during pregnancy we observed is also consistent with recent data from Australia and Canada. In a sample enrolled at mid-pregnancy in Queensland, 9\% of women met recommendations for the number of servings of vegetables and fruit ${ }^{(37)}$. In a pregnancy cohort from Ontario, $15 \% \mathrm{did}$ not meet the recommendations for minimum number of servings of any of four food groups and $4 \%$ met the minimum recommendations for all four food groups ${ }^{(38)}$.

Our findings are consistent with the data reported previously in NZ on diet and nutrient intakes during pregnancy. While differences in the dietary measurement methods used prevent direct comparisons, intakes of several micronutrients (folate, vitamin $\mathrm{B}_{6}, \mathrm{Fe}$, thiamin and $\mathrm{Zn}$ ) were potentially inadequate in studies of small samples of pregnant women from Wellington ( $n$ 115) and Dunedin ( $n$ 95) in the $1980 \mathrm{~s}^{(13,14)}$. Low intakes of vitamin D, folate, Fe and Se were 
described in a study of 196 pregnant mostly European women from a semi-urban and rural region of NZ in the $1990 \mathrm{~s}^{(13)}$. Low intakes during pregnancy of folate, riboflavin, vitamin A equivalents, $\mathrm{Ca}, \mathrm{Fe}, \mathrm{Zn}$ and Se were described from a study published in 1999 of an ethnically, socio-economically and geographically diverse sample of 504 pregnant women ${ }^{(16)}$.

In the mid-1990s, in a sample of $870 \mathrm{NZ}$ mothers of infants of appropriate size for gestational age, the proportion of women in the last month of pregnancy consuming servings of each of the main food groups that approximate current recommendations was: vegetables $\geq 3$ servings/d, $12 \%$; fruit $\geq 2$ servings/d, $53 \%$; dairy products $>3$ servings $/ d$, $50 \%$; and meat $\geq 1$ serving/d, $28 \%{ }^{(15)}$. These frequencies are similar to our findings from 2009-2010.

Of the demographic variables examined, adherence with guidelines had the strongest associations with ethnicity. Larger proportions of women of non-European ethnic groups met the minimal recommendations for number of servings of the breads/cereals and meat/eggs groups. However, this greater adherence is not matched by better nutritional status. The prevalence of obesity among Māori ( $48 \%$ ) and Pacific (60\%) women aged 15 years or older is at least twice that described in women of NZ European and other ethnic groups (24\%). Vitamin D status at birth, which is a good marker of vitamin D status during pregnancy, is poorer in non-European ethnic groups in $\mathrm{NZ}^{(8)}$.

When the associations with guideline adherence were limited to healthier choices of breads and cereals and of milk and milk products, ethnicity remained the demographic variable with the strongest associations. Of note, Māori women were more likely $(\mathrm{OR}=1 \cdot 3)$ to adhere to recommendations for healthier breads and cereals and neither Māori nor Pacific women were less likely than European women to adhere to recommendations for healthier milks.

Dietary patterns are one of the key areas of lifestyle change that occur with adoption of a Western lifestyle ${ }^{(39)}$. For example, comparisons of diet between US-born and Korean-born women living in the USA show that the US-born Korean women consumed more whole grains, red meat and nuts and had higher intakes of total fat and fat as a percentage of energy than Korean-born women ${ }^{(40)}$. Comparisons of nutritional status show that such dietary changes were likely to be having an adverse effect on health, with the proportion of overweight or obese being more than three times greater for the US-born compared with the Korean-born women ${ }^{(40)}$.

A significant proportion of NZ's population are recent immigrants. For example, $36 \%$ of the pregnant women enrolled into the Growing Up in New Zealand cohort were born overseas ${ }^{(23)}$. That such a diverse cohort has been enrolled provides new opportunities for nutrition policy development to benefit those population subgroups at greatest risk of nutrition-related health issues.

In our cohort, socio-economic disadvantage did not explain variations in adherence. Adherence with dietary recommendation did not vary with household deprivation and associations that were present with household income and maternal education did not indicate that adherence decreased as household income or maternal education decreased. In a recent Canadian pregnancy cohort the only maternal demographic characteristic predictive of adherence to food group recommendations was parity ${ }^{(38)}$.

In contrast to this lack of association with diet as described by food groups, dietary quality has been shown to be associated with maternal education and deprivation in studies performed in the UK and the USA ${ }^{(41,42)}$. The limited associations of deprivation, education and household income with food group recommendations in our study could be due to food group descriptions providing limited information on diet quality. For example, meeting or exceeding the recommendations for number of servings of the breads/cereals, milk/milk products and meat/eggs groups could be achieved with a diet that is low in fibre, high in fat and a poor source of many micronutrients.

Our choice of the FFQ to estimate intake comes with potential limitations. Most importantly, FFQ can be inaccurate due to the necessity of relying on a 'standard portion size'; methods using weighed intakes provide more accurate dietary assessments ${ }^{(43)}$. FFQ can also be problematic in that some foods may be missed, for example vegetables used in composite dishes such as casseroles or sauces. However, comparative studies have indicated that misclassification of nutrient intakes from use of an FFQ is within acceptable boundaries ${ }^{(43)}$. The ease of administering an FFQ means that in many research contexts, especially those with a large sample size, an FFQ is the only practical alternative ${ }^{(43)}$.

The relative simplicity of FFQ facilitates their use for comparisons between studies and for measurement of change in dietary practices over time. The European Diet in Pregnancy Project recognises the usefulness of the FFQ for reporting on dietary intakes in large cohort studies ${ }^{(44)}$. That project has developed a protocol for the standardisation of food group intake data from existing studies in pregnant women across Europe. Its database includes data from more than 200000 women. The protocol uses standardised FFQ and the food group descriptions are comparable to those in the present study. Thus, the less precise measurement of individual dietary consumption that an FFQ provides needs to be balanced against the greater potential for external comparability.

Our description of adherence with food group recommendations was predominantly during the third trimester of pregnancy and none of the women were interviewed during the first trimester. In the UK, nutrient intakes were shown to be similar in the first and third trimesters, and in the USA food and energy-adjusted nutrient intakes from foods alone were not appreciably different in the first compared with the second trimester ${ }^{(45,46)}$. Our data on adherence are therefore likely to be an adequate representation of dietary patterns throughout pregnancy.

Pregnancy is widely accepted as an optimal time for altering various aspects of women's lifestyles towards 
more health-promoting behaviours ${ }^{(1,47)}$. That $87 \%$ of the pregnant women in our study avoided certain foods or drinks at some point during their pregnancy implies that they were willing to make changes to their diet in order to improve their pregnancy health and the subsequent health of their infant. The relative lack of adherence to food group consumption and the relatively high frequency of consumption of foods likely to be high in fats, sugars and/ or salt are consistent with women lacking knowledge about the specific health benefits of a more nutritious diet during pregnancy. For example, while women appear to be aware of the potential maternal complications of being overweight and obese during pregnancy, many have more limited awareness of the neonatal complications ${ }^{(48)}$.

Our findings suggest that more support is needed to assist pregnant NZ women in adhering to recommended dietary patterns during pregnancy. The large variability in adherence to these guidelines between ethnic groups indicates the need for ethnicity-specific interventions that are consistent with the dietary practices and beliefs of these different groups.

\section{Acknowledgements}

Acknowledgments: The authors thank the children and the families who are part of the Growing Up in New Zealand study. They also thank all members of the Growing Up in New Zealand team, including the research and operations teams, as well as the Kaitiaki and Scientific Advisory Groups. Financial support: The authors acknowledge the key role of the Ministry of Social Development in identifying the need for a longitudinal study that reflects the diversity of today's New Zealand and for its ongoing support. Other agencies, as well as The University of Auckland, have contributed to the cost of the study to date. These are: the Ministry of Health, the New Zealand Police, the Ministry of Justice, the Families Commission, the Children's Commission, the Department of Labour, the Ministry of Education, Housing New Zealand and Sport and Recreation New Zealand. The funders have had no role in the design, analysis or writing of this article. Conflict of interest: None. Authorship: S.M.B.M. led the design, development and completion of all aspects of Growing Up in New Zealand. S.M.B.M., C.C.G. and C.R.W. designed the study reported in this manuscript. S.M.B.M., C.C.G., C.R.W., P.E.A.-C. and V.I. developed the instruments used to collect the data reported in this manuscript. D.K.B. analysed the data. S.M.B.M., C.C.G., C.R.W., P.E.A.-C., H.M.I. and C.A.C. interpreted the data. C.C.G., C.R.W. and J.M.S. compiled a first draft of the manuscript that was revised by all of the authors. C.C.G. completed the final draft of the manuscript. All authors have given their final approval for the submitted manuscript. Ethics of human subject participation: Ethical approval was obtained from the Ministry of Health Northern Y Regional Ethics Committee.

\section{Supplementary material}

To view supplementary material for this article, please visit http://dx.doi.org/10.1017/S1368980014000482

\section{References}

1. Harding JE (2001) The nutritional basis of the fetal origins of adult disease. Int J Epidemiol 30, 15-23.

2. Gluckman PD, Hanson MA \& Pinal C (2005) The developmental origins of adult disease. Matern Child Nutr 1, 130-141.

3. Black RE, Allen LH, Bhutta ZA et al. (2008) Maternal and child undernutrition: global and regional exposures and health consequences. Lancet 371, 243-260.

4. Popkin BM (2006) Global nutrition dynamics: the world is shifting rapidly toward a diet linked with noncommunicable diseases. Am J Clin Nutr 84, 289-298.

5. University of Otago \& Ministry of Health (2011) A Focus on Nutrition: Key Findings of the 2008/09 New Zealand Adult Nutrition Survey. Wellington: Ministry of Health.

6. World Health Organization (2007) Global Database on Body Mass Index. Geneva: WHO.

7. Russell DG, Parnell WR \& Wilson NC (1999) NZ Food: NZ People. Key Results of the 1997 National Nutrition Survey, Wellington: Ministry of Health.

8. Camargo CA Jr, Ingham T, Wickens K et al. (2010) Vitamin D status of newborns in New Zealand. Br J Nutr 104, 1051-1057.

9. Gartner LM \& Greer F; Section on Breastfeeding and Committee on Nutrition, American Academy of Pediatrics (2003) Prevention of rickets and vitamin D deficiency: new guidelines for vitamin D intake. Pediatrics 111, 908-910.

10. Dawodu A \& Wagner CL (2007) Mother-child vitamin D deficiency: an international perspective. Arch Dis Child 92, 737-740.

11. Ministry of Health (2006) Food and Nutrition Guidelines for Healthy Pregnant and Breastfeeding Women: A Background Paper. Wellington: Ministry of Health.

12. National Health and Medical Rresearch Council (2006) Nutrient Reference Values for Australia and New Zealand Including Recommended Dietary Intakes. Canberra: Commonwealth of Australia.

13. Benny PS, Benny SC \& Sin IL (1991) Nutrition in pregnancy in the Wellington region. $N Z$ Med J 104, 29-32.

14. McKenzie-Parnell JM, Wilson PD, Parnell WR et al. (1993) Nutrient intake of Dunedin women during pregnancy. $N Z$ Med J 106, 273-276.

15. Mitchell EA, Robinson E, Clark PM et al. (2004) Maternal nutritional risk factors for small for gestational age babies in a developed country: a case-control study. Arch Dis Child Fetal Neonatal Ed 89, F431-F435.

16. Watson P \& McDonald B (1999) Nutrition During Pregnancy: Report to the Ministry of Health. Auckland: Massey University.

17. Thompson JMD, Wall C, Becroft DMO et al. (2010) Maternal dietary patterns in pregnancy and the association with smallfor-gestational-age infants. Br J Nutr 103, 1665-1673.

18. Morton SM, Atatoa Carr PE, Grant CC et al. (2013) Cohort profile: growing up in New Zealand. Int J Epidemiol $\mathbf{4 2}$, 65-75.

19. Morton SMB, Ramke J, Kinloch J et al. (2014) Growing Up in New Zealand cohort alignment with all New Zealand births. Aust NZ J Public Health (In the Press).

20. Ministry of Health (2003) Food and Nutrition Guidelines for Healthy Adults: A Background Paper. Wellington: Ministry of Health.

21. University of Otago \& Ministry of Health (2011) Methodology Report for the 2008/09 New Zealand Adult Nutrition Survey. Wellington: Ministry of Health. 
22. Cade J, Thompson R, Burley V et al. (2002) Development, validation and utilisation of food-frequency questionnaires a review. Public Health Nutr 5, 567-587.

23. Morton SMB, Atatoa Carr PE, Bandara DK et al. (2010) Growing Up in New Zealand: A Longitudinal Study of New Zealand Children and their Families. Report 1: Before We Are Born. Auckland: University of Auckland.

24. Statistics New Zealand (2005) Statistical Standard for Ethnicity. Wellington: Statistics New Zealand.

25. Statistics New Zealand (2008) General Social Survey. Wellington: Statistics New Zealand.

26. Statistics New Zealand (2008) 2006 Census Questionnaires. Christchurch: Information Centre, Statistics New Zealand.

27. Statistics New Zealand (2013) Core Questions Module. Christchurch: Information Centre, Statistics New Zealand.

28. Salmond C, Crampton P \& Atkinson J (2007) NZDep2006 Index of Deprivation. Wellington: Department of Public Health, University of Otago.

29. White P, Gunston J, Salmond C et al. (2008) Atlas of Socioeconomic Deprivation in New Zealand NZDep2006. Wellington: Ministry of Health.

30. Perry B (2011) Household Incomes in New Zealand: Trends in Indicators of Inequality and Hardship 1982 to 2010. Wellington: Ministry of Social Development.

31. Ogunmodede F, Jones JL, Scheftel J et al. (2005) Listeriosis prevention knowledge among pregnant women in the USA. Infect Dis Obstet Gynecol 13, 11-15.

32. Rungan S \& Badkar G (2005) Listeria - how much do pregnant women really understand about it? $N Z$ Med J 118 , U1745.

33. Nurminen M (1997) Statistical significance - a misconstrued notion in medical research. Scand J Work Environ Health 23, 232-235.

34. Crozier SR, Inskip HM, Barker ME et al. (2010) Development of a 20-item food frequency questionnaire to assess a 'prudent' dietary pattern among young women in Southampton. Eur J Clin Nutr 64, 99-104.

35. Hure A, Young A, Smith R et al. (2009) Diet and pregnancy status in Australian women. Public Health Nutr 12, 853-861.

36. Crozier SR, Robinson SM, Godfrey KM et al. (2009) Women's dietary patterns change little from before to during pregnancy. J Nutr 139, 1956-1963.
37. Wilkinson SA, Miller YD \& Watson B (2009) Prevalence of health behaviours in pregnancy at service entry in a Queensland health service district. Aust N Z J Public Health 33, 228-233.

38. Fowler JK, Evers SE \& Campbell MK (2012) Inadequate dietary intakes among pregnant women. Can J Diet Pract Res 73, 72-77.

39. Satia-Abouta J, Patterson RE, Neuhouser ML et al. (2002) Dietary acculturation: applications to nutrition research and dietetics. I Am Diet Assoc 102, 1105-1118.

40. Park SY, Murphy SP, Sharma S et al. (2005) Dietary intakes and health-related behaviours of Korean American women born in the USA and Korea: the Multiethnic Cohort Study. Public Health Nutr 8, 904-911.

41. Northstone K, Emmett P \& Rogers I (2008) Dietary patterns in pregnancy and associations with socio-demographic and lifestyle factors. Eur J Clin Nutr 62, 471-479.

42. Rifas-Shiman SL, Rich-Edwards JW, Kleinman KP et al. (2009) Dietary quality during pregnancy varies by maternal characteristics in Project Viva: a US cohort. J Am Diet Assoc 109, 1004-1011.

43. Emmett P (2009) Assessing diet in longitudinal birth cohort studies. Paediatr Perinat Epidemiol 23, Suppl. 1, 154-173.

44. Mendez MA \& Kogevinas M (2011) A comparative analysis of dietary intakes during pregnancy in Europe: a planned pooled analysis of birth cohort studies. Am J Clin Nutr 94, 6 Suppl., 1993S-1999S.

45. Langley-Evans AJ \& Langley-Evans SC (2003) Relationship between maternal nutrient intakes in early and late pregnancy and infants weight and proportions at birth: prospective cohort study. $J R$ Soc Promot Health 123, 210-216.

46. Rifas-Shiman SL, Rich-Edwards JW, Willett WC et al. (2006) Changes in dietary intake from the first to the second trimester of pregnancy. Paediatr Perinat Epidemiol 20, 35-42.

47. Cox JT \& Phelan ST (2008) Nutrition during pregnancy. Obstet Gynecol Clin North Am 35, 369-383.

48. Sui Z, Turnbull DA \& Dodd JM (2012) Overweight and obese women's perceptions about making healthy change during pregnancy: a mixed method study. Matern Child Health J 17, 1879-1887. 